\title{
Psychological wellbeing and resilience among Egyptian community-dwelling older adults
}

\author{
Amira Y. Sharaf*1, Hanaa S. Ibrahim², Ola A. Lachine ${ }^{1}$ \\ ${ }^{1}$ Psychiatric Nursing and Mental Health, Faculty of Nursing, Alexandria University, Alexandria, Egypt \\ ${ }^{2}$ Gerontological Nursing, Faculty of Nursing, Alexandria University, Alexandria, Egypt
}

Received: April 26, 2019

DOI: $10.5430 /$ jnep.v9n9p55
Accepted: June 3, 2019

URL: https://doi.org/10.5430/jnep.v9n9p55

\begin{abstract}
Background: Aging represents a time of significant challenges as well as opportunities for growth. Resilience helps older adults adjust to ongoing demands of aging. Little is known, however, about individual factors that bolster resilience. This study examines the potential contribution of psychological wellbeing in building resilience in older adults.

Methods: A sample of 150 community-dwelling older adults was recruited from elder clubs in Alexandria, Egypt. Participant interviews included measures of resilience, psychological wellbeing, as well as measures of physical and psycho-social functioning.

Results: Psychological wellbeing and resilience were positively and strongly correlated $(r=.70, p<.001)$. Resilience was significantly associated with five dimensions of psychological wellbeing: mastery of environment $(r=.54, p<.001)$, self-acceptance $(r$ $=.53, p<.001)$, personal growth, and purpose in life (both $r=.49, p<.001)$, and autonomy $(r=.36, p<.001)$. A weak, but significant association was found with the sixth dimension, positive relationship with others $(r=.29, p<.001)$. Adjusting for potential confounding variables, psychological wellbeing remained significantly associated with resilience $(\beta=.59, p<.001)$. Mastery of environment $(\beta=.23, p<.01)$, autonomy $(\beta=.20, p<.01)$, personal growth $(\beta=.19, p<.01)$, and purpose in life $(\beta$ $=.18, p<.01)$, were independently influenced resilience among older adults.

Conclusions: The findings highlight the adaptive function of psychological wellbeing in boosting resilience among older adults. Nursing strategies to optimize resilience and psychological wellbeing among older adults are delineated.
\end{abstract}

Key Words: Older adults, Psychological wellbeing, Resilience

\section{INTRODUCTION}

The aging population is growing worldwide at an unprecedented rate and is expected to continue as long as the mortality age continues to decline. According to the latest data provided by the United Nation (2017), the aging population comprises $13 \%$ of the global population. The number of older adults is expected to be 1.4 billion by 2030 and 2.1 billion by 2050, and may rise to 3.1 billion by 2100 .
The 2017 Egyptian census indicated that 8\% of the Egyptian population was 60 years and older. This percentage is projected to increase to $9.8 \%$ by $2030,12.6 \%$ by 2050 , and $16.3 \%$ by $2100 .^{[1]}$ Increasing life expectancy is often associated with particularly distressing adversities. ${ }^{[2-4]}$ For instance, aging is accompanied by frailty with decline in physical and cognitive functioning, and an increase in multiple chronic diseases. ${ }^{[5,6]}$ In addition, older adults experience

\footnotetext{
* Correspondence: Amira Y. Sharaf; Email: amira_psych@yahoo.com; Address: Faculty of Nursing, Psychiatric Nursing and Mental Health Department, Alexandria, Egypt.
}

Published by Sciedu Press 
psychological stress resulting from loss and bereavement, ${ }^{[7]}$ decline in socioeconomic status with retirement, disability, ${ }^{[8]}$ as well as concomitant loss of autonomy and depression. ${ }^{[9,10]}$ Such challenges influence social functioning, and erode one's sense of wellbeing.

Paradoxically, a growing body of evidence suggests that despite losses and functional declines, some older adults adjust to these challenges and hardships with a high level of wellbeing, ${ }^{[2,11]}$ and perceive themselves to be aging successfully. ${ }^{[12,13]}$ Recent research has turned a focus to positive aspects of aging, personal strengths, and gains associated with aging. ${ }^{[4,13,14]}$ Resilience is an internal psychological resource that facilitates older adults' ability to cope with ageing-related challenges. ${ }^{[9]}$ Resilience is the ability to stand up to adversity, to "bounce back" and return to a state of equilibrium following adversity, ${ }^{[15]}$ with a strong sense of purpose, perseverance and competence. ${ }^{[16]}$ Some studies conceptualized resilience as a personality trait that mitigates the adverse effect of stress, promotes adaptation, and contributes to independent functioning and wellbeing. ${ }^{[17,18]}$ Others conceive of resilience as an adaptive process comprising a constellation of psychosocial factors, ${ }^{[19-21]}$ that facilitate older adults in negotiating and managing stress, thereby reducing further function disabilities. ${ }^{[2]}$ Review of the aging literature indicates that resilience is associated with being physically active, ${ }^{[4,23]}$ better physical health and fewer chronic illnesses, ${ }^{[9,10]}$ strong social support, ${ }^{[21,24]}$ adaptive coping, ${ }^{[12,20]}$ and lower depression. ${ }^{[12,25]}$

Psychological wellbeing is another key protective factor, ${ }^{[14,26,27]}$ recognized as not only simply as attaining of pleasure and happiness, but also striving to fulfill one's true potential. ${ }^{[28,29]}$ Ryff and Keyes (1995) conceptualized psychological wellbeing as a multidimensional construct comprised of six dimensions: environmental mastery, selfacceptance, personal growth, purpose in life, autonomy, and positive relationship with others. ${ }^{[29]}$ Evidence suggests that psychological wellbeing contributes to adaptive functioning and positive experiences. ${ }^{[30]}$ Well documented is the fact that individuals with a high degree of mental health are most able to counteract negative experiences in life. ${ }^{[13]}$ Archer et al. (2015) reported that among Singaporean older adults, psychological wellbeing buffered the negative effect of stress on health. ${ }^{[31]}$ Extensive research indicates that positive emotions - the constitutive elements of an individual's sense of wellbeing - facilitate adaptive recovery. ${ }^{[32-34]}$ Little research, however, has examined psychological wellbeing as antecedent to resilience. For instance, Lamond et al. (2008) found that the strongest predictors of resilience among older adults living in community were emotional wellbeing, optimism, self-rated successful aging, social engagement, and lower cognitive dysfunction. ${ }^{[35]}$ Similarly, McKibbin et al. (2016) reported that mental health was the strongest predictor of resilience among older adults living in rural and remote communities. ${ }^{[24]}$ Still unexamined is if and how psychological wellbeing is associated with and influences resilience in elder populations.

This study sought to examine associations between psychological wellbeing and resilience among Egyptian communitydwelling older adults. Evidence-based results are needed to assist policy makers and health care professionals in developing specific strategies to build, sustain, and enhance resilience through psychological wellbeing. Such approaches will assist older adults in adjusting to unavoidable challenges to aging with optimal functioning, thereby maximizing opportunities for successful aging. Two specific research questions were addressed: 1) Is there an independent relationship between psychological wellbeing and resilience among Egyptian community-dwelling older adults, taking into account known socio-demographic and health-related correlates of resilience? 2) Which dimensions of psychological wellbeing are most strongly associated with resilience, adjusting for potential socio-demographic and health-related correlates?

\section{Methods}

\subsection{Design and setting}

Using a cross-sectional design, the study was carried out at governmental elder clubs in Alexandria, Egypt. At the time of data collection, five of six existing clubs were able to participate in the study, involving approximately 200 older adult members. Each club serves its surrounding catchment area and provides a variety of programs and supportive services for older adults, including social and recreational activities (e.g., picnics, parties, etc.), religious programs, health education programs, fitness programs, cultural activities (e.g., music, painting, reading, etc.), as well as health care services such as monitoring and referring older adults with chronic diseases to appropriate services. All services are affiliated with the Ministry of Social Affairs in Egypt as a part of empowering healthy aging. Clubs are open daily except Friday, from 9 AM to $6 \mathrm{PM}$.

\subsection{Sampling and participants}

A convenience sample of community-dwelling older adults with membership in the elder clubs in Alexandria was recruited. Older adults, available at the time of the study (n $=175$ ), were screened based on eligibility criteria. Older adults age 60 and more, able to communicate in a coherent and relevant manner $(n=160)$ were invited to participate. Of these, 150 older adults met eligibility criteria and were willing to participate in the study. 


\subsection{Measures}

\subsubsection{Resilience}

Resilience in older adults was measured using the 10item, abbreviated version of Connor-Davidson Resilience Scale (CD-RISC) developed by Campbell-Stills and Stein (2007). ${ }^{[36]}$ Each item was scored on a 5-point response scale ranging from 0 (not true at all) to 4 (true most of the time). Items were summed to create a total score with a range from 0 to 40, with higher values denoting greater resilience. The scale has established validity and reliability in older adults. ${ }^{[4,37]}$ In the current study, Cronbach's alpha was .88 .

\subsubsection{Psychological wellbeing}

Psychological wellbeing was assessed using the short version of the psychological wellbeing scale. ${ }^{[28]}$ The scale consists of 18-item and six subscales (3-item each) measuring environmental mastery (ability to competently manage one's life), self-acceptance (positive attitude toward oneself and one's past life), personal growth (open to new experiences and feelings of continued self improvement overtime), purpose in life (has goals in life and believes one's life is meaningful), autonomy (independence and self-determination), and positive relationship with others (having warm and satisfying relationship with others). ${ }^{[29]}$ The response scale is a 6-point continuum, ranging from 1 (strongly disagree) to 6 (strongly agree). The total score across subscales ranges from 18 to 108 , with higher scores indicating greater sense of psychological wellbeing. Scale validity and reliability has been established, and the scale has been used in studies of older adults. ${ }^{[38,39]}$ In the current study, the internal consistency reliability for the total scale score was acceptable at .78.

\subsubsection{Physical and psycho-social functioning}

A structured interview schedule was developed to assess older adults' physical functioning, such as the presence and types of chronic diseases, vision and hearing problems, mobility, and history of fall(s). Psycho-social functioning was assessed using dichotomous self-report items inquiring about hobbies, emotional support, and feelings of loneliness. Older adults who reported feeling lonely rated their degree of loneliness using an ordinal scale ranging from 1 (mild) to 3 (severe).

\subsubsection{Demographic variables}

A brief structured interview was used to elicit demographic information including age, gender, marital status, level of education, and income.

\subsection{Ethical considerations}

Study procedures were reviewed and approved by the Ethical and Human Subjects Protection Committee of the Faculty of Nursing, Alexandria, Egypt. In addition, written permission to conduct the study was obtained from the Ministry of Social Affairs in Alexandria, and from the directors of the elder clubs included in the study. In describing the study to potential participants, the researcher informed the prospective participants that their participation would be fully voluntary and emphasized that their privacy would be protected, their interview responses would be confidential, stored as anonymous data, and used only for the purpose of this study. Written informed consent was obtained from all study participants who were eligible and willing to participate. If a participant was illiterate, a fingerprint was used in the lieu of a signature, witnessed by an administrative staff member at the elder clubs.

\subsection{Data collection}

Psychological Wellbeing and Resilience Scales were translated into Arabic following the protocol described by Sharaf et al. (2012). ${ }^{[40]}$ To ensure the clarity of translated measures and the applicability of the developed structured interviews, a pilot study was conducted with 15 older adults. Preliminary results showed the feasibility and the applicability of all study measures. The sample of the pilot study was included in the main study since no measurement modifications were required.

Over a two-month period, study researchers met with older adults to introduce the study purpose during club activities. Older adults who agreed to participate and signed the informed consent were interviewed individually and administered the study instruments in a private location by one of the researchers. Each interview was completed within 20-30 minutes.

\subsection{Analysis}

Descriptive statistics (e.g., frequency, mean, SD, skew, kurtosis) were computed to examine distributions of the variables and to summarize the characteristics of the study sample. Pearson product moment correlation coefficients, t-tests and ANOVA were used to examine for associations between resilience, psychological wellbeing and its dimensions, and other variables including socio-demographic factors and measures of physical and psycho-social functioning.

To address research question \#1, hierarchical regression analysis was conducted in four steps to identify whether psychological wellbeing had an independent influence on resilience, adjusting for potential covariates. Psychological wellbeing was entered (step 1) followed by potential covariates including the indicators of physical functioning (step 2), psychosocial functioning (step 3), and socio-demographic variables (step 4).

To address research question \#2, a single block regression 
analysis was conducted to elucidate which dimensions of psychological wellbeing had independent effects on resilience. That is, the dimensions of psychological wellbeing were entered into the analyses simultaneously with the above covariates. Standardized regression coefficients $(\beta)$ were used to estimate the effect of each dimension on resilience. Level of significance set at $p<.05$, two-tailed.

\section{RESUltS}

\subsection{Socio-demographic characteristics}

Participants' ages ranged from 60 to 85 years, with a mean of 69.1 years $(\mathrm{SD}=6.0)$. Nearly three quarters of the sample (75.3\%) were females. Sixty-eight percent of the older adults were widowed or divorced. Years of education ranged from 0 to 20 years with a mean of 12.3 years $(\mathrm{SD}=3.9)$. The vast majority of the sample $(90 \%)$ reported that their income was enough to satisfy their needs.

\subsection{Physical and psycho-social functioning}

Eighty-six percent of the sample $(n=129 / 150)$ had one or more chronic diseases. The most common diseases were hypertension (71\%) and diabetes mellitus (48\%). Of these 129 study participants, $65.9 \%(n=85)$ had more than one chronic disease. The majority of the older adults (88.7\%) wore eyeglasses and $79 \%$ had no hearing problem. Eightyfive percent of the participants were mobile. Nearly half of the sample $(43.3 \%)$ had a previous history of fall(s), the number ranging from 1 to 7 falls with a mean of 2.9 (SD = 1.5) falls.

Concerning psycho-social functioning, $78 \%$ of the older adults received emotional support from their families/friends. More than half of the sample $(55.3 \%)$ engaged in hobbies. The majority (88\%) spent leisure time interacting and participating in social activities with one other inside and outside of the elder clubs. One third of the sample (33\%) described their leisure time as watching TV and listening to the radio. Another $30 \%$ preferred to spend their leisure time in praying, and/or reading the Quran or Bible either in mosques/churches or with friends. Significantly, half of older adults $(n=76)$ reported feelings of loneliness. Of these, a notable proportion $(26.3 \%, \mathrm{n}=20)$ reported severe loneliness.

\subsection{Psychological wellbeing and resilience}

On average, study participants reported a moderate degree of resilience $(\mathrm{M}=24.0, \mathrm{SD}=8)$ and psychological wellbeing $(\mathrm{M}=80.7, \mathrm{SD}=13.80)$. Psychological wellbeing and resilience were strongly correlated $(r=.70, p<.001)$. Generally, the correlations between resilience and five dimensions of psychological wellbeing were positive and moderate to strong for: mastery of environment $(r=.54, p<.001)$, self- acceptance $(r=.53, p<.001)$, personal growth, purpose in life (both $r=.49, p<.001)$, and autonomy $(r=.36, p<$ $.001)$. Associations between resilience and positive relationship with others $(r=.29, p<.001)$ was slightly weaker but also significant.

\subsection{Examining for potential covariates}

Bivariate analyses revealed that among socio-demographic variables, only gender and years of education were linked to resilience. Male older adults reported significantly higher resilience $(\mathrm{M}=27.3, \mathrm{SD}=5.5)$ than females $(\mathrm{M}=22.9, \mathrm{SD}$ $=8.5 ; t=3.67, p<.001)$. Years of education was positively associated with resilience $(r=.43, p<.001)$. Regarding physical functioning, resilience was negatively associated with the number of chronic diseases $(r=-.17, p<.05)$. Resilience was significantly higher among older adults who were mobile with or without the need of walking assistance $(\mathrm{M}=24.8, \mathrm{SD}=7.6)$ than those who needed a wheelchair $(\mathrm{M}=19.5, \mathrm{SD}=8.9 ; t=2.67, p<.05)$. Conversely, those with a history of falls were less resilient $(\mathrm{M}=22.3, \mathrm{SD}=8.5)$ than those with no history $(\mathrm{M}=25.3, \mathrm{SD}=7.5 ; t=-2.24, p$ $<.05)$.

For psycho-social functioning, resilience was higher among those who did not report loneliness $(\mathrm{M}=27.4, \mathrm{SD}=6.5)$ versus those who did $(\mathrm{M}=20.7, \mathrm{SD}=8.1 ; t=-5.62, p<.001)$. Also, older adults who engaged in hobbies were significantly more resilient $(\mathrm{M}=26.6, \mathrm{SD}=6.3)$ than those who did not $(\mathrm{M}=21.9, \mathrm{SD}=8.7 ; t=-3.86, p<.001)$.

\subsection{Examining the independent relationship between psychological wellbeing and resilience (Research Question\#1)}

Table 1 presents results of the fourth and final step of the hierarchical regression examining the unadjusted and adjusted effects of psychological wellbeing on resilience. In step 1, psychological wellbeing was significantly associated with resilience $(\beta=.70, p<.001)$, accounting for $48 \%$ of the variation in the resilience. In step 2 , with the inclusion of health-related variables, psychological wellbeing remained significantly associated with resilience $(\beta=.69, p<.001)$, explaining $51 \%$ of the variance in resilience. In step 3 , with the inclusion of related psycho-social variables, the association between resilience and psychological wellbeing remained significant $(\beta=.60, p<.001)$, with an increase of explained variance to $55 \%$. In step 4 , in which socio-demographic variables were added, the significant relationship between resilience and wellbeing persisted $(\beta=.59, p<.001)$; the combined effect of all variables explained $58 \%$ of the variance in resilience, adding $3 \%$ of explained variance above the step 3 model $(F[2,141]=24.6, p<.001)$. 
Table 1. Hierarchical regression (final step 4) examining the relationship between psychological wellbeing and resilience among community-dwelling older adults $(\mathrm{N}=150)$

\begin{tabular}{llll}
\hline Predictors & B & SEB & $\boldsymbol{\beta}$ \\
\hline Psychological wellbeing & .34 & .04 & $.59 * * *$ \\
Mobility $(1=$ mobile, $0=$ use wheelchair) & -.19 & 1.34 & -.01 \\
Number of chronic diseases & -.05 & .42 & -.01 \\
Previous falls $(1=$ yes, $0=$ no) & -1.42 & .93 & -.01 \\
Feeling of loneliness $(1=$ yes, $0=$ no) & -2.14 & .99 & $-.13^{*}$ \\
Practicing hobbies $(1=$ yes, $0=$ no) & 1.75 & .93 & .11 \\
Gender $(1=$ male, $0=$ female) & 3.10 & 1.09 & $.17 * *$ \\
Years of education & .15 & .13 & .07 \\
\hline$* p<.05 ; * * p<.01 ; * * p<.001$. & & &
\end{tabular}

\subsection{Testing the independent influence of dimensions of psychological wellbeing on resilience (Research Question\#2)}

A single block regression analysis, including the six dimensions of psychological wellbeing and covariates simultaneously (see Table 2), revealed that mastery of environment $(\beta=.23, p<.01)$ had the strongest influence on resilience, followed by autonomy $(\beta=.20, p<.01)$, personal growth $(\beta$ $=.19, p<.01)$, and purpose in life $(\beta=.18, p<.01)$. With all dimensions of psychological wellbeing in the analysis, two dimensions - self-acceptance and positive relationship with others-were not predictive of resilience.

Table 2. Single block regression: influence of six dimensions of psychological wellbeing on resilience among community-dwelling older adults $(\mathrm{N}=150)$

\begin{tabular}{|c|c|c|c|}
\hline Predictors & $\mathbf{B}$ & SEB & $\boldsymbol{\beta}$ \\
\hline \multicolumn{4}{|l|}{ Dimensions of Psychological Wellbeing } \\
\hline Mastery of environment & .70 & .20 & $.23 * *$ \\
\hline Self-acceptance & .17 & .16 & .08 \\
\hline Personal growth & .37 & .13 & $.19 * *$ \\
\hline Purpose in life & .40 & .15 & $.18 * *$ \\
\hline Autonomy & .39 & .11 & $.20 * *$ \\
\hline Positive relationship with others & .13 & .15 & .05 \\
\hline \multicolumn{4}{|c|}{ Physical, Psycho-social and Socio-demographic Covariates } \\
\hline Mobility (1 = mobile, 0 = use wheelchair) & -.40 & 1.34 & -.02 \\
\hline Number of chronic diseases & -.07 & .42 & -.01 \\
\hline Previous falls $(1=$ yes, $0=$ no $)$ & -1.52 & .95 & -.09 \\
\hline Feeling of loneliness $(1=$ yes, $0=$ no $)$ & -2.06 & .99 & $-.13^{*}$ \\
\hline Practicing hobbies $(1=$ yes, $0=$ no $)$ & 1.66 & .96 & .10 \\
\hline Gender ( 1 = male, 0 = female $)$ & 2.73 & 1.12 & $.15^{*}$ \\
\hline Years of education & .17 & .13 & .08 \\
\hline
\end{tabular}

\section{Discussion}

The results of this study revealed that psychological wellbeing was independently associated with resilience among

Published by Sciedu Press
Egyptian community-dwelling older adults. These findings mirror the role of psychological wellbeing in adaptation. But how is this so? Psychological wellbeing tends to increase the likelihood of momentary experience of positive emotions (e.g., feelings of happiness, joy, contentment, and satisfaction with life), which in turn may help elderly to reframe and manage adversities associated with aging. Thus, older adults, in the present study, may draw on positive emotions associated with psychological wellbeing to mobilize adaptive coping strategies when encountering aging-related stressors. This interpretation is supported by Fredrickson's (2001) broadened theory of positive emotions. ${ }^{[41]}$ She postulated that the experience of positive emotions tends to open up momentary thought $\rightarrow$ action repertoires, which serves to build enduring personal resources, specifically intellectual, social and psychological coping strategies to manage life adversities. Highlighting this, the broadened effect of positive emotions on cognition may increase the likelihood that older adults perceive challenges related to aging in a less threatening manner, and are thus able to generate effective problem-solving strategies. Congruent with this interpretation, Gloria and Steinhardt (2016) in their study of the relationships among positive emotions, coping, resilience, and mental health found that positive emotions indirectly enhance resilience through strengthening adaptive coping and offsetting maladaptive strategies. ${ }^{[42]}$ Similarly, Folkman and Moskowitz (2000) found that positive emotions mitigated the effect of stress through processes of positively reappraising stress, enacting problem-focused coping, and trying new experiences/activities to elicit positive meaning. ${ }^{\text {[3] }}$

Regarding the specific dimensions of psychological wellbeing, current findings showed that mastery of environment, autonomy, personal growth, and sense of purpose in life were all independently associated with resilience among older adults. This result indicates that older adults who demonstrated self-reliance, were goal oriented, and optimized their personal experience with mastery, may rely on such inner strengths to mobilize flexible and creative problem solving strategies to restore balance in their lives. This interpretation is reflected in other research that has demonstrated a positive association between resilience and problem-focused coping. ${ }^{[19,26,42,43]}$ On the other hand, the adaptive function of self-acceptance in promoting resilience may initially be contingent on awareness of one's inner resources of independency, personal potential, and competence in achieving goals with mastery across the trajectory of life. That is, across life experiences, older adults come to realize their capabilities to manage life circumstances independently and in a way congruent with their needs and values. This in turn motivates the elderly to persevere and face life stres- 
sors with the knowledge of their strengths and limitations, bounded by self-acceptance. Supporting this explanation, Ryff (2014) postulated that wellbeing is honed and nurtured through confronting hardships. For instance, when a person encounters adversities, personal growth-realization of one's potential- might paradoxically enlarge awareness of one's limitations. ${ }^{[44]}$

Contrary to multiple studies that have posited social resources as important determinant of resilience among older adults, ${ }^{[3,21,24]}$ the current findings revealed a weak association between having a positive relationship with others and resilience. In addition, this effect disappeared when this dimension was considered simultaneously with the other dimensions of wellbeing. Two possible interpretations are possible. First, the influence of social resources on resilience may not only derive from the positive experience of relationship with others, but may also extend from the subjective feelings of being useful to others, especially to the next generations. In the current study, most of the older adults were still contributing to their household finances. Moreover, older adults in the Egyptian culture are considered precious members of the community as they disseminate the wisdom of life experiences, reaffirm cultural values, reinforce traditional identities, and are provide significant caregiving for grandchildren. For elders, the virtue of caring, derived from generativity, may also promote resilience through enhancing unique identity and sense of self. Browne-Yung et al. (2017), using a narrative method to examine the relationship between resilience and sense of self-identity among Australian elderly, highlighted a similar notion, pointing out that social connectedness with younger generations fosters resilience by enhancing a feeling of being respected and sense of existential purpose. ${ }^{[45]}$

Second, the link between social relationships and resilience may be indirect, moderated or buffered by the effects of social relationship on existential loneliness associated with becoming old. Engaging in meaningful interactions/activities with others inside/outside elder clubs may strengthen a sense of belonging and universality, counteracting loneliness, building resilience to confront life challenges. The results shown in Table 2 correspond to this interpretation, as the bolstering effect of positive relationships on resilience became nonsignificant after adjusting for relevant covariates, including feeling of loneliness. Also relevant, the Gerino's et al. (2017) finding indicated that loneliness was negatively associated with resilience in a sample of older adults. ${ }^{[46]}$ Longitudinal studies are needed to examine the potential mediating and moderating roles of loneliness in explaining the relationship between resilience and social resources among older adults. In brief, the results of the current study suggest that inner resources may play a more significant role in promoting resilience among older adults than do external resources.

\section{Conclusion}

Psychological wellbeing is a salient psychological asset that can reinforce resilience in older adults. Mastery of environment, autonomy, personal growth, and purpose in life are useful resources in helping older adults adapt with ongoing stress of aging.

\subsection{Study strengthens and limitations}

A novel aspect of the current study is that it focused on positive aspects of aging, illustrating that older adult may remain functionally adaptive through the inner strength of psychological wellbeing. In addition, the findings pointed to specific intervention strategies, discussed below, that can assist health care providers in maximizing the capabilities of older adults in successful aging. Interpretations of the findings, however, necessitate consideration of study shortcomings. First, the current study was conducted with a sample of community-dwelling older adults who participated in elder clubs. Therefore, the findings cannot be generalized to the institutionalized elderly, as additional studies are needed in this respect. Second, because the data were cross-sectional, it was difficult to disentangle cause and effect relationships between key study variables. For instance, the robust association between psychological wellbeing and resilience among older adults may be bidirectional. It is also possible to infer that resilient elderly who demonstrate flexible and creative adaptation are more likely to build confidence in dealing with challenges in aging and thus contribute to more positive outcomes, which in turn enhances feelings of happiness, and satisfaction with life. This premise coincides with Fredrickson and Joiner (2000, cited by Fredrickson) who found that a reciprocal relationship between positive emotions and resilience sparked an upward spiral, enhancing psychological wellbeing. ${ }^{[41]}$ Longitudinal studies will be needed to establish causal order. Third, the resilience scale is not a situation-specific measure. Thus, to draw conclusions about resilience and the capacity to bounce back from adversities, stressors that the elderly face also need to be assessed and incorporated in analyses.

\subsection{Implications for nursing practice}

The findings highlight the need to develop interventions to strengthen psychological wellbeing and concomitantly forge resilience in older adults. Strong evidence indicates that strategies used to cultivate positive emotions, a central facet of wellbeing, can foster psychological wellbeing and resilience among older adults. ${ }^{[14,47]}$ In this respect, Smith and Hollinger-Smith (2014) found that savoring, the capacity 
to elicit positive moments in one's life by directing one's attention to positive experiences, predicted psychological wellbeing among older adults in terms of greater happiness and satisfaction with life, and lower levels of depressive symptoms. ${ }^{[14]}$ Interventions that optimize positive emotions include the promotion of positive thinking via reframing of adverse events, and the incorporation of momentary feeling of happiness into one's frame of reference. Assisting older adults in acknowledging life blessings and expressing optimism and gratitude also boost happiness. ${ }^{[48]}$

On a behavioral level, engaging in meaningful activities through elder clubs, especially volunteering activities that allow elderly to examine their potentials and demonstrate acts of kindness, can promote sense of altruism and perseverance in the face of adversities. Interestingly, Lynos et al. (2016) found that older adults who sensed their influence on others during community group sessions were more resilient than those who did not. They postulated that a greater sense of personal influence may foster competency and mastery of environment. ${ }^{[49]}$ Accordingly, a feasible approach is to shape interventions that engage older adults in activities that specifically enhance a sense of caring for others, and actively allow participation in decision-making processes.

\section{ACKNOWLEDgements}

A special thanks to the older adults who participated in this study and inspired us to learn the art of life. We extend our sincerest appreciation to the administrative staff of elder clubs for their genuine help and support during data collection. Deepest appreciation to Emeritus Professor Elaine Thompson, University of Washington, School of Nursing for her valuable feedback on the earlier version of this manuscript and proofreading the final version.

\section{CONFLICTS OF INTEREST Disclosure}

The authors declare that they have no competing interests.

\section{REFERENCES}

[1] United Nations Department of Economic and Social Affairs/Population Division 21 World Population Prospects: The 2017 Revision, Key Findings and Advance Tables. Available from: https://esa.un.org/unpd/wpp/publications/files /wpp2017_keyfindings.pdf

[2] Cosco TD, Howse K, Brayne C. Healthy ageing, resilience and wellbeing. Epidemiol Psychiatr Sci. 2017 Dec; 26(6): 579-83. PMid: 28679453 https://doi.org/10.1017/S2045796017000324

[3] Wells M. Resilience in older adults living in rural, suburban, and urban areas. Online Journal of Rural Nursing and Health Care. 2010; 10 (2): 45-54. https://doi.org/10.14574/ojrnhc.v10i2.55

[4] Rantanen T, Saajanaho M, Karavirta L, et al. Active aging-resilience and external modifiers of the disablement outcome: AGNES cohort study protocol. BMC Public Health. 2018 May; 18(1): 565. Available from: https://bmcpublichealth.biomedcentral.com/trac k/pdf/10.1186/s12889-018-5487-5 PMid:29716566 https: //doi.org/10.1186/s12889-018-5487-5

[5] Vaingankar JA, Chong SA, Abdin E, et al. Prevalence of frailty and its association with sociodemographic and clinical characteristics, and resource utilization in a population of Singaporean older adults. Geriatr Gerontol Int. 2017 Oct; 17(10): 1444-54. PMid: 27576598 https://doi.org/10.1111/ggi.12891

[6] Shamliyan T, Talley KM, Ramakrishnan R, et al. Association of frailty with survival: a systematic literature review. Ageing Res Rev. 2013 Mar; 12(2): 719-36. PMid: 22426304 https ://doi .org/10 $.1016 / j$.arr.2012.03.001

[7] Hashim SM, Eng TC, Tohit N, et al. Breavement in the elderly: the role of primary care. Ment Health Fam Med. 2013 Sep; 10(3): 159-62. PMid: 24427183

[8] Poterba JM. Retirement security in an ageing population. AM ECON REV. 2014; 104(5): 1-30. https://doi.org/10.1257/aer.104. 5.1

[9] Wells M. Resilience in rural community-dwelling older adults. J Rural Health. 2009 Fall; 25(4): 415-9. PMid:19780924 https: //doi.org/10.1111/j.1748-0361.2009.00253.x
[10] Jest DV, Savla GN, Thompson WL, et al. Association between older age and more successful aging: critical role of resilience and depression. Am J Psychiatry. 2013 Feb; 170(2): 188-96. PMid: 23223917 https://doi.org/10.1176/appi.ajp.2012.12030386

[11] Windle G. The contribution of resilience to healthy ageing. Perspect Public Health. 2012 July; 132(4): 159-60. PMid: 22729003 https://doi.org/10.1177/1757913912449572

[12] Gooding PA, Hurst A, Johnson J, et al. Psychological resilience in young and old adults. Int J Geriatr Psychiatry. 2012 Mar; 27(3): 26270. PMid: 21472780 https ://doi.org/10.1002/gps . 2712

[13] Nygren B, Alex L, Jonsen E, et al. Resilience, sense of coherence, purpose in life and self-transcendence in relation to perceived physical and mental health among oldest old. Aging Ment Health. 2005 Jul; 9(4): 354-62. PMid: 16019292 https ://doi .org/10.1080/ 1360500114415

[14] Smith JL, Hollinger-Smith L. Savoring, resilience, and psychological well-being in older adults. Aging Ment Health. 2014; 19(3):192-200. PMid: 25471325 https : //doi.org/10.1080/13607863.2014. 986647

[15] Netuveli G, Wiggins RD, Montgomery SM, et al. Mental Health and resilience at older ages: bouncing back after adversity in the British household panel survey. J Epidemiol Community Health. 2008; 62 (11): 987-91. PMid: 18854503 https://doi.org/10.1136/je ch. 2007.069138

[16] Southwick SM, Bonanno GA, Masten AS, et al. Resilience definitions, theory, and challenges: interdisciplinary perspectives. Eur J Psychotraumatology. 2014 Oct; 5: 253-38 PMid: 25317257 https://doi.org/10.3402/ejpt.v5.25338

[17] Wagnild GM, Young HM. Development and psychometric evaluation of the resilience scale. JNM. 1993 Winter; 1(2): 165-78. PMid: 7850498

[18] Connor KM, Davidson JRT. Development of a new resilience scale: the Connor-Davidson Resilience Scale (CD-RISC). Depression Anxiety. 2003; 18(2): 76-82. PMid:12964174 https ://doi.org/10.1 002/da. 10113 
[19] Kessel GV. The ability of older people to overcome adversity: a review of the resilience concept. Geriatr Nurs. 2013 Mar-Apr; 34(2): 122-7. PMid: 23332474 https ://doi.org/10.1016/j.gerinu rse.2012.12.011

[20] Macleod S, Musich S, Hawkins K, et al. The impact of resilience among older adults. Geriatr Nurs. 2016 Jul-Aug; 37(4): 266-72. PMid: 27055911 https ://doi.org/10.1016/j.gerinurse .20 16.02 .014

[21] Bolton KW, Praetorius RT, Smith-Osborne A. Resilience protective factors in an older adult population: a qualitative interpretative meta-synthesis. Social Work Research. 2016; 40(3): 171-82. https://doi.org/10.1093/swr/svw008

[22] Windle G. What is resilience? A review and concept analysis. Rev Clin Gerontol. 2011; 21(2): 152-69. https ://doi.org/10.1017/ S0959259810000420

[23] Childs E, de Wit H. Regular exercise is associated with emotional resilience to acute stress in healthy adults. Front Physiol. 2014; 5(161) PMid: 24822048 https ://doi.org/10.3389/fphys.2014.001 61

[24] McKibbin C, Lee A, Steinman BA, et al. Health status and social networks as predictors of resilience in older adults residing in rural and remote environments. Journal of Aging Research. 2016 Jun; Article ID 4305894, 8 pages. Available from: https://www.hind awi.com/journals/jar/2016/4305894/ref/ PMid:27478639 https://doi.org/10.1155/2016/4305894

[25] Lim ML, Lim D, Gwee X, et al. Resilience, stressful life events, and depressive symptomatolgy among older Chinese adults. Aging Ment Health. 2015; 9(11): 1005-14. PMid: 25559786 https : //doi.org/10.1080/13607863.2014.995591

[26] Tomas JM, Sancho P, Melendez JC, et al. Resilience and coping as predictors of general well-being in the elderly: a structural equation modeling approach. Aging Ment Health. 2012 April; 16(3): 317-26. PMid: 22292552 https://doi.org/10.1080/13607863. 2011. 615737

[27] de Paula Couto MCP, Koller SH, Novo R. Stressful life events and psychological well-being in a Brazilian sample of older persons: the role of resilience. Ageing Int. 2011 Dec; 36(4): 492-505. https://doi.org/10.1007/s12126-011-9123-2

[28] Ryff CD. Happiness is everything, or is it? Explorations on the meaning of psychological well-being. J Pers Soc Psychol. 1989; 57(6): 1069-81. https://doi.org/10.1037/0022-3514.57.6.1069

[29] Ryff CD, Keyes CL. The structure of psychological well-being revisited. J Pers Soc Psychol. 1995; 69(4): 719-27. https ://doi .org/ 10.1037/0022-3514.69.4.719

[30] Cloninger CR, Salloum IM, Mezzich JE. The dynamic origins of positive health and wellbeing. Int J Pers Cent Med. 2012 Jun; 2(2): 179-87. PMid: 26140189 https : //doi.org/10.5750/ijpcm.v2 i2. 213

[31] Archer JA, Tony Lim ZM, Teh HC, et al. The effect of age on the relationship between stress, well-being and health in a Singaporean sample. Ageing Int. 2015 Sep; 40(4): 413-25. https: //doi.org/10.1007/s12126-015-9225-3

[32] Tappolet C, Rossi M. Emotions and wellbeing. Topoi. 2015; 34(2): 461-74. https://doi.org/10.1007/s11245-013-9234-3

[33] Cohn MA, Fredrickson BL, Brown SL, et al. Happiness unpacked: positive emotions increase life satisfaction by building resilience. Emotion. 2009 June; 9(3): 361-68. PMid: 19485613 https ://doi org/10.1037/a0015952

[34] Tugade MM, Fredrickson BL. Resilient individuals use positive emotions to bounce back from negative emotional experience. $\mathrm{J}$ Pers Soc Psy. 2004 Feb; 86(2): 320-33. PMid: 14769087 https: //doi.org/10.1037/0022-3514.86.2.320
[35] Lamond AJ, Depp C, Allison M, et al. Measurement and predictors of resilience among community-dwelling older women. J Psychiat Res. 2008 Jan; 43(2): 148-54. PMid: 18455190 https : //doi.org/10.1016/j.jpsychires.2008.03.007

[36] Campbell-Stills L, Stein MB. Psychometric analysis and refinement of the Connor-Davidson Resilience Scale (CD_RISC): validation of a 10-item measure of resilience. J Trauma Stress. 2007 Dec; 20(6): 1019-28. PMid: 18157881 https://doi.org/10.1002/jts. 20 271

[37] Schure MB, Odden M, Goins RT. The association of resilience with mental and physical health among older American Indians: the native elder care study. Am Indian Alsk Ment Health Res. 2013; 20(2): 27-41. PMid: 23824641 https://doi.org/10.5820/aian. 200 2.2013 .27

[38] Kirby SE, Coleman PG, Daley D. Spirituality and well-being in frail and nonfrail older adults. J Gerontol B Psychol Sci Soc Sci. 2004 May; 59(3): 123-9. PMid: 15118015 https ://doi.org/10.109 3/geronb/59.3.P123

[39] Keyes CL, Shmotkin D, Ryff CD. Optimizing well-being: the empirical encounter of two traditions. J Pers Soc Psychol. 2002 Jun; 82(6): 1007-22. PMid: 12051575 https ://doi .org/10.1037//0022-3 514.82 .6 .1007

[40] Sharaf AY, Ossman LH, Lachine OA. A cross-sectional study of the relationships between illness insight, internalized stigma, and suicide risk in individuals with Schizophrenia. Int J Nurs Stud. 2012 Dec; 49(12): 1512-20. PMid: 22939218 https://doi.org/10.1016/ j.ijnurstu.2012.08.006

[41] Fredrickson BL. The role of positive emotions in positive psychology: the broaden-and-build theory of positive emotions. Am Psychol. 2001March; 56(3): 218-26. PMid: 11315248 https: //doi.org/10.1037//0003-066X.56.3.218

[42] Gloria CT, Steinhardt MA. Relationships among positive emotions, coping, resilience and mental health. Stress Health. 2016 Apr; 32(2): 145-56. PMid: 24962138 https ://doi .org/10.1002/smi . 2589

[43] Folkman S, Moskowitz JT. Positive affect and the other side of coping. Am Psychol. 2000 Jun; 55(6): 647-54. PMid:10892207 https://doi.org/10.1037//0003-066X.55.6.647

[44] Ryff CD. Self-realization and meaning making in the face of adversity: a eudaimonic approach to human resilience. J Psychol Afr. 2014; 24(1): 1-12. PMid: 25435804 https ://doi.org/10.1080/1433 0237.2014 .904098

[45] Browne-Yung K, Walker RB, Luszcz MA. An examination of resilience and coping in the oldest old using life narrative method. The Gerontologist. 2017 April; 57(2): 282-91. PMid: 26511273 https://doi.org/10.1093/geront/gnv137

[46] Gerino E, Rolle L, Sechi C, et al. Loneliness, resilience, mental health, and quality of life in old age: a structural equation model. Front Psychol. 2017 Nov; 8, Article ID 2003. https : //doi .org/ 10.3389/fpsyg. 2017.02003

[47] Fredrickson BL. Cultivating positive emotions to optimize health and well-being. Prevention \& Treatmen. 2000 March; 3(1). https : //doi.org/10.1037//1522-3736.3.1.31a

[48] Weiting NG. Boosting well-being with positive psychology interventions: moderating role of personality and other factors. J Contemp Psychother. 2015; 45(2): 79-87. https://doi.org/10.1007\%2F s10879-014-9291-y

[49] Lyons A, Fletcher G, Farmer J, et al. Participation in rural community groups and links with psychological well-being and resilience: a cross-sectional community-based study. BMC Psychol. 2016 April; 4: 16. Available from: https://www.ncbi.nlm.nih.gov/pmc/a rticles/PMC4826495/pdf/40359_2016_Article_121.pdf 